\title{
A NEW GENUS AND SPECIES OF VERMILEONIDAE (DIPTERA: BRACHYCERA) FROM MADAGASCAR
}

\begin{abstract}
Stuckenberg, B. R., 2002. A new genus and species of Vermileonidae (Diptera, Brachycera) from Madagascar. - Tijdschrift voor Entomologie 145: 1-8, figs. 1-8. [ISSN 0040-7496]. Published 1 June 2002.

The new genus Isalomyia is erected for a new species, I. irwini, discovered in the Isalo Range of south-western Madagascar, the first vermileonid known from that island. Morphological adaptations of the proboscis for nectarivory show this taxon to be part of the Gondwanan monophylum of genera. Only the female of I. irwini is known, so a full account of Isalomyia and an assessment of its relationships cannot be given yet. The antennal form is plesiomorphic, but the remarkable way in which sensilla on the flagellomeres are distributed is distinctive and apomorphic. The wing venation shares features with the Omani species Lampromyia umbraticola Stuckenberg \& Fisher, 1999, but these may be plesiomorphies. I. irwini was found in a topographically unique area with sandstone inselbergs and outcrops on the eastern margin of the Permo-Triassic sediments in western Madagascar. Landforms produced by erosion-resistant sandstone formations may provide durable larval habitats for vermileonid faunas. Such landforms are significant for vermileonid biogeography in South Africa, and could prove to be important in Madagascar.
\end{abstract}

B. R. Stuckenberg, Department of Arthropoda, Natal Museum, P. Bag 9070, Pietermaritzburg 3200, South Africa. E-mail: bstucken@nmsa.org.za

Keywords. - Vermileonidae; Isalomyia new genus; Madagascar; sandstone habitat.

The family of wormlion flies, Vermileonidae, appears to be a relict from Jurassic times and has an unusual biogeography (Stuckenberg 2000). It constitutes the infraorder Vermileonomorpha of the homeodactylous Brachycera, and is currently considered to be without close living relatives (Griffiths 1994, Stuckenberg 2001). The family probably dispersed during the Jurassic and Early Cretaceous. The known world fauna divides into Laurasian and Gondwanan components, with monophyly of the Gondwanan section demonstrated by synapomorphies in the male genitalia, and in elongation and other adaptations of the proboscis for flower-visiting and nectar-extraction (Stuckenberg 2000, 2001). The Laurasian component is widely though irregularly distributed in several biogeographical regions, occurring in the western Palaearctic Region and in China, and extending into the Oriental tropics in India, Malaysia, Borneo and Sumatra. In the Americas, it occurs in the south-western United States, Mexico, Guatemala, Costa Rica and some Caribbean islands (Nagatomi et al. 1999, provide a catalogue of the world fauna). With such a long history, it has been anomalous that the Gondwanan clade appeared to be restricted to Africa and Arabia, apart from two probably Late Miocene vicariant extensions from north-west Africa into Iberia
(Stuckenberg 1998, 2000). No vermileonids have been found in the other Gondwana landmasses, except for a species of the Oriental genus Vermitigris Wheeler, 1930, which includes India in its distribution (Oldroyd 1947). However, unexpected discoveries have shown that vermileonids may be overlooked for many years: it was only in 1979 that the speciose Chinese genus Vermiophis Yang was described, and the presence of the family in the Arabian Peninsula was reported recently (Stuckenberg \& Fisher 1999).

The occurrence of Vermileonidae in Madagascar is the latest discovery. Two wormlions were collected by Dr M. E. Irwin while searching for therevid larvae in the Isalo Range during December 1999, and were sent to me for rearing. One was in an early instar and unfortunately died, but the other was more mature and transformed into a female fly that emerged on 12 April 2001. This serendipitous find is potentially of great interest in view of the remarkable and often enigmatic biogeographical characteristics of the island. The fly is described below as representing a new genus and species, Isalomyia irwini.

It remains to be seen whether more vermileonid species will be found in Madagascar. Although this is an ancient, continental part of Gondwana, its Dipteran fauna is strangely unbalanced. Two other orthor- 
rhaphous families similarly have only one known species in Madagascar. These are Mydidae, represented by Afroleptomydas seyrigi Séguy, 1960, found in southern Madagascar (Bowden 1980, transferred the species from Leptomydas Gerstaecker, 1868, to Afroleptomydas Bequaert, 1961, which is a large, otherwise Southern African genus); and Nemestrinidae, with Nycterimyia seyrigi Séguy, 1951, recorded from several localities in the eastern rainforest region (Nycterimyia is palaeotropical, ranging from South Africa to Queensland). The niche for large nectar-feeding flies seems to be poorly filled in Madagascar.

\section{TERMINOLOGY AND METHODS}

Standard morphological terminology is used. $\mathrm{T}=$ tergite, $S=$ sternite. The wing illustrated in fig. 7 was deliberately flattened in balsam under a coverslip, so that the position of crossvein sc-r could be seen. The spermathecae were exposed after maceration of the apical part of the abdomen in hot $\mathrm{KOH}$ and subsequent irrigation in water. After examination in water at low magnifications, they were transferred to warm glycerine-jelly which unfortunately caused them to shrink and distort. The spermatheca illustrated in fig. 3 is a reconstruction based on rough sketches made under low magnification, and subsequent examination at high magnifications in glycerine-jelly; the drawing may not be completely accurate. The coloring of the holotype was described after the specimen had been in ethanol for several weeks; it may not have developed its mature coloration by the time when it was preserved, and some loss of colour intensity may have resulted from preservation in the liquid.

Nomenclature of antennal components follows Stuckenberg (1999). In that study it was shown that the African vermileonid genera preserve all stages in a transformation series ranging from taxa in which the primitive flagellum with eight flagellomeres is present, to the most derived forms having flagellomeres 1-6 fused into a postpedicel with an olfactory chemosensory role, supporting an apical style composed of flagellomeres 7 and 8 which has a mechanoreceptor role. It was found that both chemoreceptor and mechanoreceptor sensilla may be present on flagellomeres 1-7 or 1-6 in taxa with the primitive complement of eight flagellomeres.

\section{RELATIONSHIPS AND CLASSIFICATION}

In recent publications (Stuckenberg 2000, 2001), I postulated that the Gondwanan vermileonid lineage is strongly established as monophyletic. Among its autapomorphies are specialisations of the proboscis for nectarivory: the labium has become slender and elongate to varying degrees, the labella are corre- spondingly modified into narrow, tubular forms, and the number of pseudotracheal branches has been extremely reduced. In the most derived forms, there is only a single, bifid pseudotrachea per labellum. Associated with this, the clypeus projects anteriorly, the most prominent clypeal forms occurring in the taxa with great elongation of the labium. Isalomyia is certainly a member of this lineage, as it has these proboscis modifications and strongly protruding clypeus (fig. 1), so its relationships must be sought among the African clades. The female holotype has the following notable features:

Antennal segmentation (fig. 5). - Eight flagellomeres are present, so no postpedicel has evolved; not only is this the primitive number in Brachycera, but another primitive condition is also present in that flagellomeres 1-7 have both chemoreceptor and mechanoreceptor sensilla (fig. 4). The terminal flagellomere 8 appears to have only tactile sensilla, so it has only a mechanoreceptor role for which its more slender form is appropriate. The only other vermileonid clades retaining eight flagellomeres are Vermipardus Stuckenberg, 1960, and Vermilynx Stuckenberg, 1995, both of Southern Africa; these two genera are distinctive and are not closely related to Isalomyia or to one another (see the conspectus of genera by Stuckenberg 2000).

Distribution of antennal sensilla (figs 4, 5). - The flagellum is relatively large, laterally flattened, and densely covered along the entire dorsal surface of flagellomeres 1-7 by tactile sensilla that appear to form almost a continuous proclinate layer. The terminal flagellomere has these sensilla over its entire surface. The only antennal form that warrants comparison is that of the Omani species Lampromyia umbraticola Stuckenberg \& Fisher, 1999. Its antenna (fig. 6) is unique in having flagellomeres 1-6 fused into an exceptionally extended and enlarged postpedicel, bearing apically an unusually small style formed as shown of flagellomeres 7 and 8. It is also unique in having a strip of dense sensory vestiture dorsally along the entire length of the postpedicel, shown diagrammatically in fig. 6 . In both I. irwini and I. umbraticola there is thus a comparable and evidently apomorphic distribution of sensilla, although their flagellar segmentation is entirely different.

Wing (fig. 7). - The wings of I. irwini and I. umbraticola are similar in shape and certain features of venation; in I. umbraticola (see Stuckenberg 2000, fig. 22), its short petiole and unspecialised form, retention of the crossvein $\mathrm{m}-\mathrm{cu}$, narrow fork of $\mathrm{R}_{4}$ and $\mathrm{R}_{5}$, and short radial-sector, are plesiomorphic (Stuckenberg \& Fisher 1999); I. irwini has similar conditions, although the radial fork is wider. Possibly all these resemblances are plesiomorphies. In I. irwini, crossvein sc-r is unusually close to h, whereas in $I$. umbraticola it is about midway between the levels of $h$ and the point of origin of the radial-sector (the usual 
placement in Vermileonidae: see Stuckenberg 2001).

Spermatheca (fig. 3). - (See terminology and methodology above.) Apparently stoutly disc-shaped, more strongly sclerotised in a peripheral band, with a concavity proximally in which the duct is inserted, and a more thinly sclerotised, domed distal surface.

These morphological conditions of the female show that this Madagascan species is unrelated to the genera endemic in Southern Africa. The only remaining possibility is the seemingly more widespread genus Lampromyia Macquart, 1835, but this genus presents systematic problems. Formerly, it was the only recognised African genus characterised by an elongate proboscis (Bezzi 1926, Stuckenberg 1960), but, with the removal of most of the South African species to new genera, it has become a taxonomic residue composed of four quite disparate and geographically widely disjunct groups of species (Stuckenberg 2000). These four groups are: the L. pilosula group of Southern Africa (three species); the $c a$ nariensis group of the Canary Islands (three species); the cylindrica group of north-west Africa, extending into Iberia (six species); and the monotypic umbraticola group of Oman. No way of uniting them cladistically as a demonstrably monophyletic genus is evident, so Lampromyia is probably polyphyletic. The best solution to this problem would be to accord generic status to each of the groups. Rather than adding yet another species-group to Lampromyia as an ad hoc and a provisional taxonomic solution, it is better to accept the morphological features of I. irwini described above to be of generic significance.

This conclusion is supported by the distinctiveness of the spermathecal structure. It is now known that most of the groups of species ranked as vermileonid genera in Southern Africa each has its own form of spermatheca (Stuckenberg 2000). Also, each of the species-groups currently in Lampromyia has a distinctive spermatheca (Stuckenberg 1998, Stuckenberg \& Fisher 1999). These forms cannot be ordered into a transformation series. The plain spherical type might be plesiomorphic, as it is structurally the most simple one and occurs in a few lineages that are not otherwise close morphologically (for example, the $c a-$ nariensis group and the Southern African genus Perianthomyia Stuckenberg, 1996). All the other spermathecal types, with specialisations such as extended membranous sacs, or minute spicules on the outer surface of the bulb, seem to be apomorphic in unique ways and therefore could be good evidence for monophyly, supporting the use of combinations of external characters whose individual polarity may be indeterminate. Being internal structures, spermathecae are unlikely to be affected by adaptive pressures arising from conditions in the external environment that could result in homoplasies. These perceptions are supported in studies on Bombyliidae by Greathead, who made use of spermathecal structure for the definition of monotypic lineages in the poorly understood Lomatiini (Greathead 1998) and in the paraphyletic Bombyliuss. lat. (Greathead 1995).

\section{TAXONOMY}

\section{Genus Isalomyia gen. n.}

Type species: Isalomyia irwini sp. $\mathrm{n}$.

\section{Etymology}

Isalo, the Malagasy name for the strangely eroded mountain range where the type species was found, appropriately marked on many maps as Massif Ruiniforme de l'Isalo, with myia (G.) a fly; feminine.

\section{Diagnosis}

Distinguished from all other known African genera with a slender, elongate proboscis by the character states of the antenna, wing and spermatheca.

\section{Description}

Antenna with eight flagellomeres, apical flagellomere much shorter and narrower than preceding one, most flagellomeres laterally compressed; flagellomeres 1-7 densely covered dorsally with proclinate sensilla, and laterally and ventrally with clearly separated, suberect, anteriorly curved sensilla set in pale, shallow, circular pits; apical flagellomere only with setiform mechanoreceptor setae, these abundant over entire surface. Proboscis elongate, slender; labella elongate, narrow, tubular, closely appressed, apparently each with only a bifid pseudotrachea. Wing venation unspecialised; crossvein $\mathrm{m}-\mathrm{cu}$ present, crossvein sc-r positioned relative to humeral crossvein as shown in fig. 7, fork of $\mathrm{R}_{4}$ and $\mathrm{R}_{5}$ quite narrow; wing not strongly petiolate; radial-sector only as long as basal section of $\mathrm{R}_{4+5}$. Pulvilli very small, mediolobus vestigial. Female T9 exposed, not concealed beneath T8; spermatheca as in fig 3 .

\section{Isalomyia irwini sp.n.}

(figs. 1-5, 7)

A predominantly pale yellowish fly with unpatterned, almost clear wings; mesonotum and dorsum of abdomen with pattern of small, dark markings as shown in fig. 2, the paired longitudinal stripes on the pronotum distinctive; The prominently erect antennae contribute to the distinctive appearance of the fly.

Holotype: Female: MADAGASCAR, Tulear Prov; $1075 \mathrm{~m} / 3 \mathrm{~km} \mathrm{~W}$ Ranohira, SE edge Isalo/ National Park; 17.xii.1999/ sieved from shelf under cliff/ overhang; M. E. Irwin \& E. I./ Schlinger; 22.56254'S, 


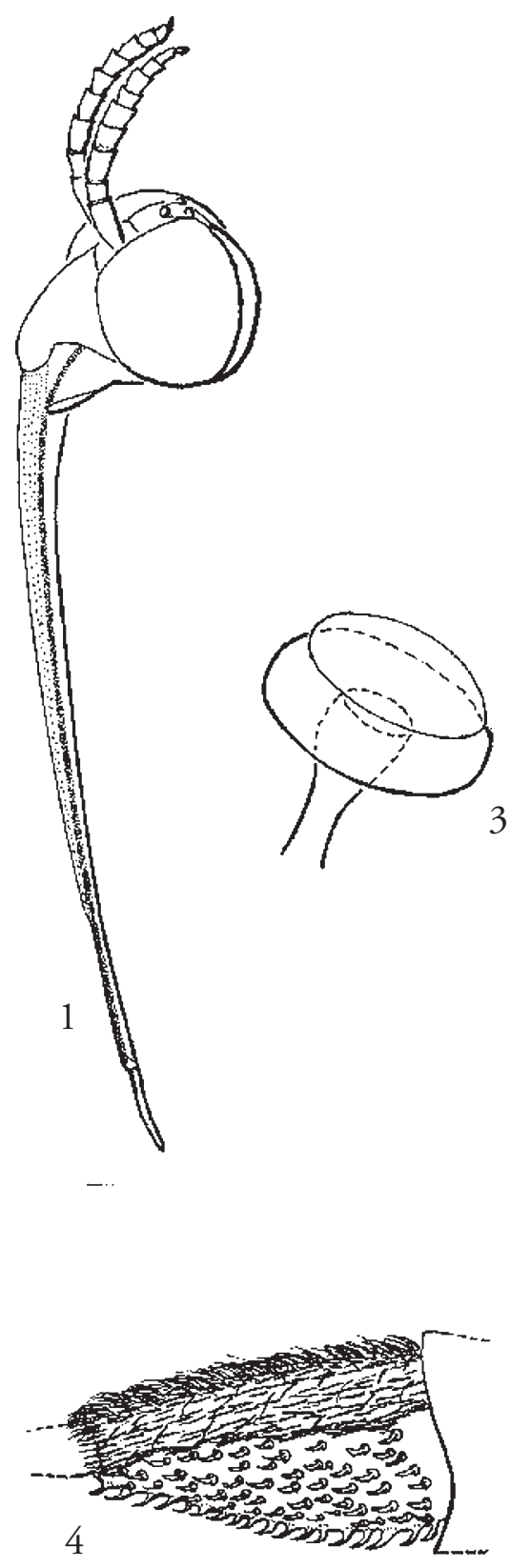

2

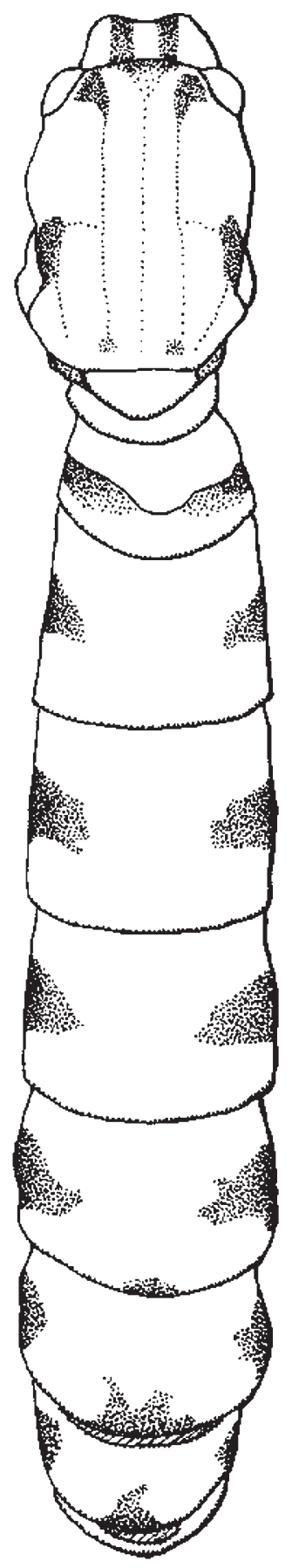

Figs 1-4. Isalomyia irwini sp. n. - 1, Head in anterolateral view; 2, Thorax and abdomen in dorsal view, showing pattern; 3 , Spermatheca, reconstructed; 4, Flagellomere 7, lateral view, showing distribution of two types of sensilla. 
45.38411'E [rectangular printed label]. In Natal Museum, type no. 2298; preserved in ethanol, one wing and antenna in Canada balsam on microscope slide. Collected as larva, reared in Merrivale by BRS; fly emerged on 12.iv.2001.

\section{Description}

Head (fig. 1). - Subglobular in lateral view; occiput sparsely setose, swollen and broadly exposed over lower part; ocellar tubercle positioned over central part of head where vertex is rounded and slightly concave so that tubercle is not visible in lateral view; frons very short, about as long as ocellar tubercle, parallelsided, width about one-quarter of head width. Clypeus projecting strongly, subtriangular in lateral view, pale yellowish-brown. Proboscis very slender, in life directed obliquely backwards between fore and middle legs, brown, about $3.3 \mathrm{x}$ length of mesonotum, labella very slender, closely appressed, about $15 \%$ of total proboscis length; pseudotrachea extending to apex of labella and apparently bifid. Antennae (fig. 5) conspicuously bicolored, scape and pedicel uniformly pale brownish yellow, flagellum dark brown; scape widening slightly towards apex; pedicel short, about half of scape length, broadened below; segmentation of flagellum unmodified, eight segments retained, flagellomeres laterally compressed so that individual flagellomeres appear broad; basal flagellomere the longest, about equal to combined lengths of flagellomeres 2 and 3, succeeding flagellomeres becoming shorter and gradually narrower, maintaining an almost straight edge along dorsal surface, flagellomere 5 and those following progressively longer than broad, flagellomere 7 strongly and asymmetrically narrowed apically; terminal flagellomere reduced and much narrower, tapering gradually to a rounded apex. Flagellomeres 1-7 (fig. 5) with dense dorsal covering of distally-directed, semirecumbent tactile setae, in microscope slide preparation appearing as a dark strip over dorsal surface, this strip widening proximally on first flagellomere; flagellomeres 1-7 laterally and ventrally with many clearly separated, suberect, distally curved, translucent chemoreceptor setae set in pale, circular, shallow pits (as in fig. 4).

Thorax (fig. 2). - Dorsally pale orange-brown, with pattern of small, dark brown markings as follows: pronotum with pair of longitudinal stripes; mesonotum with subtriangular markings inwards of and narrowly separated from humeral calli, these markings extended dorsocentrally into a point; a roughly oval spot on lateral declivity above wing base. Scutellum pale yellowish, postnotum similar, both unmarked. Most of mesopleuron and all of sternopleuron light brownish, posterior pleura contrastingly paler. Fore coxae creamy-yellowish with slight brownish infusion; mid and hind coxae similar but more strongly diffused with brown on upper surface; fore and middle legs pale creamy-yellow, tarsomeres slightly darkened; hind legs pale brownish with poorly defined apical quarter of tibia dark brown. All trochanters apically, and all femora basally, with narrow blackish border.

Wing (fig. 7). - Clear and unpatterned except for weak apical infumescence, subcostal cell slightly brown-tinged, veins dark brown; petiole short, anal lobe almost symmetrically tapering at both ends; radial-sector about as long as basal part of $\mathrm{R}_{4+5}$ (from divergence of $R_{2+3}$ to $r-m$ ); $R_{2+3}$ with anterior curvature as shown; $\mathrm{R}_{4}$ with strong basal flexure; cell $\mathrm{m}_{3}$ strongly narrowed apically; crossvein sc-r placed about onethird of distance between $\mathrm{h}$ and origin of radial-sector.

Abdomen (fig. 2). - Tergites pale orange with brownish tinge; patterned with small dark markings situated against lateral margins at about midlength of each tergite, as illustrated; all tergites except T1 with fine, small, dark, recumbent setae over apical part which occupies about half of length of T2-5 and larger area of T6 and T7; basal portion of each of these tergites bare. Sternites uniformly pale yellowish; S1 bare, other sternites with small, brown, recumbent setae; $S 8$ short, with a median triangular projection in hind margin which is demarcated on each side by a concave excision. Spermathecae (fig. 3) three in segment 7 , pale brown; shaped like stout discs, thickened in a peripheral band, concave proximally with duct inserted centrally, apical surface domed and thin.

Measurements. - Body length $10.9 \mathrm{~mm}$; wing length $7.5 \mathrm{~mm}$; proboscis length $4.5 \mathrm{~mm}$.

\section{Etymology}

Named in honour of Dr Mike Irwin whose skill as a collector revealed the presence of this vermileonid in Madagascar.

\section{THE SIGNIFICANCE OF SANDSTONE TOPOGRAPHY FOR VERMILEONID BIOGEOGRAPHY}

The type locality of $I$. irwini is in the Isalo National Park, a region with remarkable scenery and rich endemic flora and fauna. This park encloses the Isalo Range which forms part of the eastern margin of the expanse of almost horizontal sedimentary geological strata covering a large part of western Madagascar (fig. 8). Elsewhere, the surface of the island is formed by igneous rocks in complex suites making up the Precambrian basement. These sediments dip gradually westwards, and the oldest members are exposed narrowly along the eastern margin; these geological formations are equivalent to the vast Karoo Supergroup of South Africa, of Lower Permian to Jurassic age (Brenon 1972). Presumably this Madagascar manifestation of the Karoo strata was once contiguous with that in Africa, when the island in its predrift position was part 

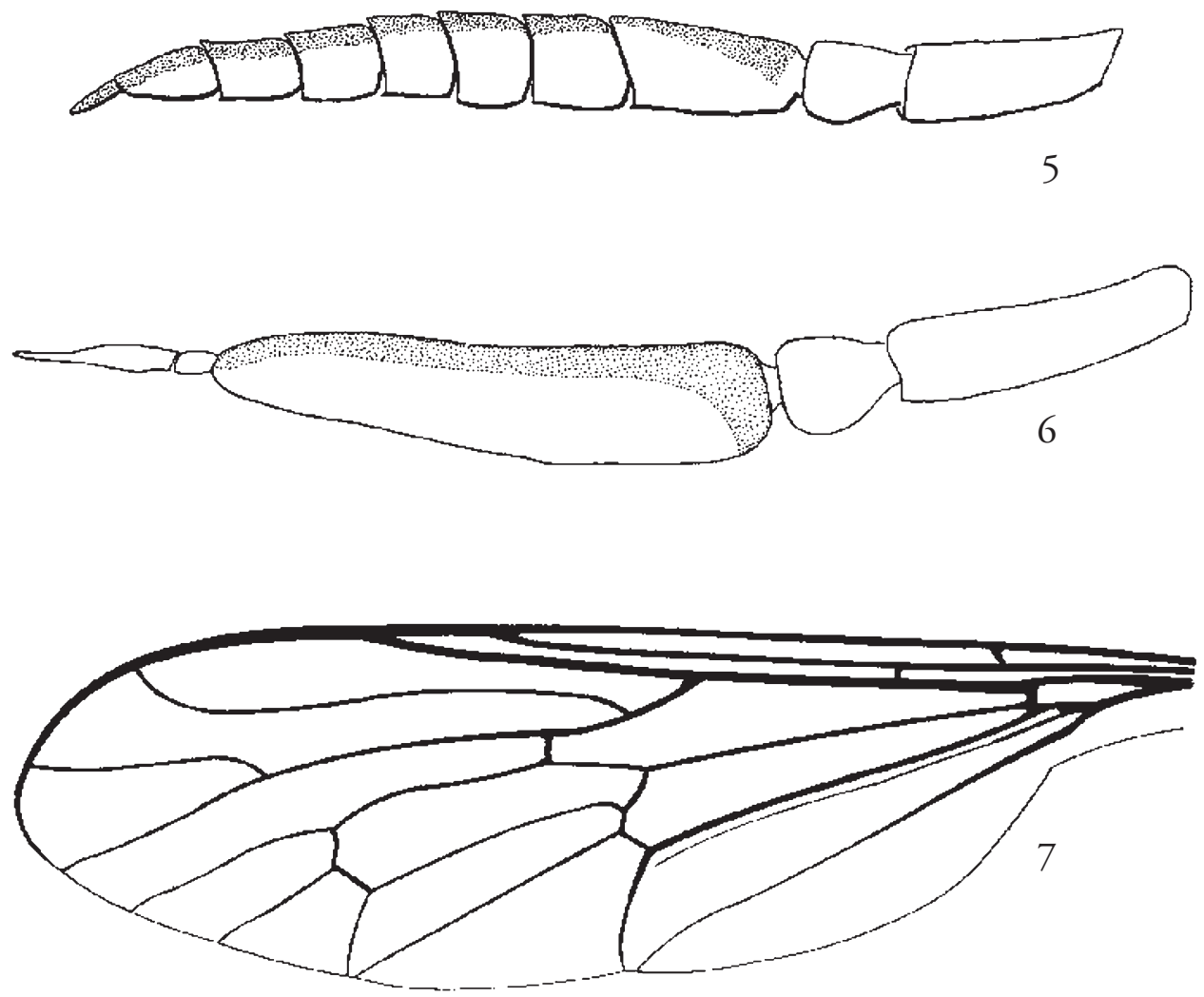

Figs 5-7. Isalomyia irwini sp. n. - 5, Antenna in lateral view, dorsal surface densely covered by proclinate tactile setae indicated by stippling; 6, Lampromyia umbraticola Stuckenberg \& Fisher, Antenna in lateral view, area of postpedicel with dense sensory vestiture indicated by stippling; 7, Isalomyia irwini sp. n., Wing venation.

of the Kenya/Tanzania region (Lawver et al. 1998). In South Africa, this series includes a thick Jurassic sandstone named the Clarens Formation. The analogous sandstone in Madagascar, which contributes to the distinctive topography of the Isalo Range, is designated Isalo I, the oldest member of the Isalo Group, and is dated Upper Triassic (Brenon 1972).

During the period 24 January to 4 February 1958 , I collected in the same place visited by Dr Irwin, outside the town of Ranohira (fig. 8). The Isalo Range formed a prominent western skyline, and proved to be a dissected cuesta with flat-topped mountains scattered in an intricate maze of valleys. There were large mesas, some at a distance resembling modern blocks of apartments with horizontal ridging giving the effect of balconies. To the east, the approach to the range was over a level grassland from which arose sandstone inselbergs emerging steeply and abruptly from the soil. Their surface was sculpted and eroded in an extraordinary way, stated by Brenon (1972) to have been caused by wind-blown sand. At various levels were horizontal ledges, cavities and small caves. A distinctive flora was confined to those rock masses.

Some of the caves and overhung ledges could have provided a habitat suitable for wormlions, being sheltered from rain and direct sunlight, and with fine, dry, loose sand in which they could construct their pitfall traps. Dr Irwin discovered the wormlions while sieving substrate from an overhung shelf. Despite intensive collecting of flies in that area, I never found a vermileonid. However, their period of adult activity in the Isalo may correspond to the time of emergence of the reared holotype of I. irwini in South Africa (mid-April), and it may coincide with late-summer 


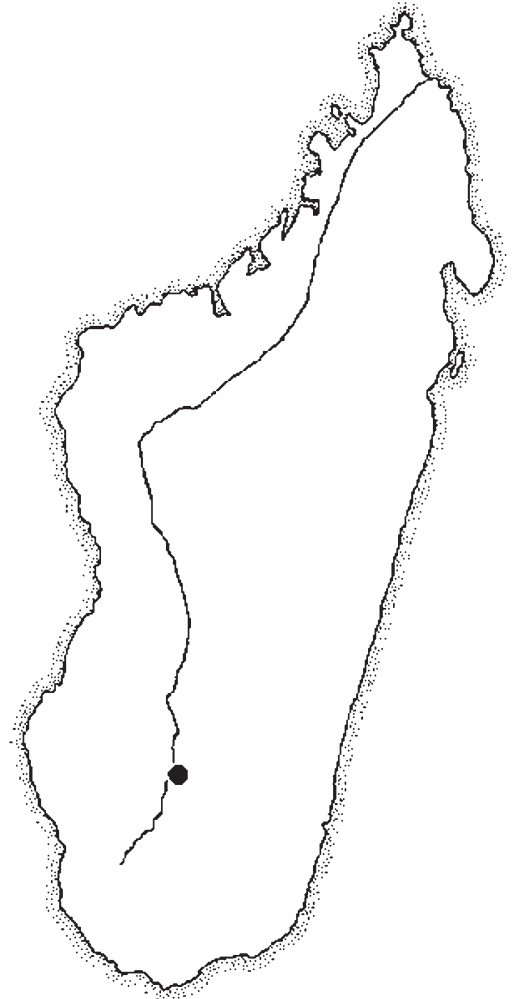

Fig. 8. Map of Madagascar. - The eastern border of the sedimentary strata covering much of the western part of the island is shown by the line; the position of Ranohira on the outskirts of the Isalo Range is indicated by the solid circle.

flowering of particular plants in the range that are adapted for pollination by such flies.

My observations of vermileonid biogeography in eastern South Africa have revealed that large sandstone formations often provide suitable, long-enduring habitats for vermileonid larvae, especially where these strata are horizontal or nearly so (Stuckenberg 1995). Undercutting commonly occurs at the base of cliffs and other sandstone exposures, creating caves or sheltering overhangs. Horizontal lines of weakness at various levels may also be eroded out into ledges protected from sun and rain by overhanging rock. These are typical features of the Drakensberg escarpment in KwaZuluNatal (South Africa), which is the product of headwater erosion of the entire sequence of strata constituting the enormously thick Karoo Supergroup which dips slightly to the west. There is an erosion-resistant sand- stone called the Clarens Formation, which has created a characteristic landscape of cliff-bound spurs projecting from the main escarpment. Such scenery is repeated continuously along the Drakensberg because of the uniform nature and horizontality of the strata. In places, blocks of sandstone have fallen away from the cliffs, and these sometimes provide permanent cover over bare ground whose constant protection allows the accumulation of fine, loose soil in which wormlions can live and make their traps. This is an ancient landform: the geomorphological evolution of the Drakensberg began with the rifting apart of South Africa and Antarctica in the Jurassic, when a seaward-facing scarp was initiated, which then slowly eroded westwards throughout the entire Cretaceous (Partridge \& Maud 1987). It could have provided persisting and continuously renewed habitats suitable for vermileonids, and for forest and aquatic invertebrates. Also in KwaZuluNatal, an older sandstone formation - the Natal Group - forms elevated topography close to the coast, with cliffs, ravines, caves and overhangs, where endemic vermileonid species occur, different to those in the Drakensberg. One cave, investigated by archaeologists, had evidence in its floor deposits of Late Pleistocene (ca.100 000 years BP) occupation by Middle Stone Age cultures (Kaplan 1990), and could have sheltered wormlions for that entire period or even longer.

A similar geomorphological evolution evidently occurred along the eastern margin of the equivalent sandstone strata in Madagascar. This margin probably previously lay further to the east, with scarp formation developing after the separation of India and Madagascar in the mid-Cretaceous. The almost horizontal Isalo sandstone would have contributed from an early stage to the shaping of the landscape. Sandstone inselbergs like those near Ranohira, which are relicts of former positions of the scarp, could have been an ancient feature. This would have been one of the most likely landforms in which vermileonids could become established and maintain a presence in Madagascar.

\section{ACKNOWLEDGEMENTS}

Thanks are due to Dr Mike Irwin of the University of Illinois for entrusting me with the live wormlions he found in Madagascar, and for donating the holotype of I. irwini to the Natal Museum. I am grateful to my supportive colleagues Dr Jason Londt and Dr David Barraclough for encouraging my research programme, and for reviewing a draft of this paper. The willingness of Dr David Greathead of London to share his insights into the value of spermathecal structures for systematics is much appreciated. Ms Catherine Conway is thanked for her technical help and artwork. 


\section{REFERENCES}

Bezzi, M.,1926. South African Rhagionidae (Diptera) in the South African Museum. - Annals of the South African Museum 23: 297-324.

Bowden, J., 1980. [Chapter] 27. Family Mydidae. - In: R. W. Crosskey (ed.). Catalogue of the Diptera of the Afrotropical Region. - British Museum (Natural History), London: pp. 325-333.

Brenon, P., 1972. The Geology of Madagascar. - In: R. Battistini \& G. Richard-Vindard (eds.). Biogeography and Ecology in Madagascar. - W. Junk, The Hague: pp. 27-86.

Greathead, D. J., 1995. A review of the genus Bombylius Linnaeus s. lat. (Diptera: Bombyliidae) from Africa and Eurasia. - Entomologica Scandinavica 26: 47-66.

Greathead, D. J., 1998. A review of the Afrotropical and Palaearctic genera of Lomatiinae (Diptera: Bombyliidae). - Entomologica Scandinavica 29: 211-222.

Griffiths, G. C. D., 1994. Relationships among the major subgroups of Brachycera (Diptera): a critical review. Canadian Entomologist 126: 861-880.

Kaplan, J. 1990. The Umhlatuzana Rock Shelter sequence: 100000 years of Stone Age history. - Natal Museum Journal of Humanities 2: 1-94.

Lawver, L. A., L. M. Gahagan, \& I. W. D. Dalziel, 1998. A tight fit-Early Mesozoic Gondwana, a plate reconstruction perspective. - In: Y. Motoyoshi \& K. Shiraishi (eds.). Origin and Evolution of Continents. - Memoirs of National Institute of Polar Research, Special Issue, 53: 214-229.

Nagatomi, A., C. Yang \& D. Yang, 1999. The Chinese species and the world genera of Vermileonidae (Diptera). - Tropics. Monograph Series 1: 154 pp. Japan Society of Tropical Ecology, Osaka.

Oldroyd, H., 1947. A new Vermitigris (Diptera: Rhagionidae) from Borneo. - Proceedings of the Royal Entomological Society of London (Ser. B) 16: 21-22.

Partridge, T. C. \& R. R. Maud, 1987. Geomorphic evolution of southern Africa since the Mesozoic. - South
African Journal of Geology 90: 179-208.

Stuckenberg, B. R., 1960. Diptera (Brachycera) Rhagionidae. - South African Animal Life 7: 216-308.

Stuckenberg, B. R., 1995. A taxonomic revision of Vermipardus Stuckenberg, 1960, with descriptions of new species and notes on the biology and biogeography of the genus (Diptera: Vermileonidae). - Annals of the Natal Museum 36: 215-253.

Stuckenberg, B. R., 1998. A revision of the Palaearctic species of Lampromyia Macquart (Diptera, Vermileonidae), with the description of a new Iberian species and a cladogram for the genus. - Bonner Zoologische Beiträge 48: 67-96.

Stuckenberg, B. R., 1999. Antennal evolution in the Brachycera (Diptera), with a reassessment of terminology relating to the flagellum. - Studia Dipterologica 6: 33-48.

Stuckenberg, B. R., 2000. Namamyia, a new genus of Vermileonidae (Diptera) from Namaqualand, with a conspectus of the South African genera and an account of their adaptations for anthophily. - Annals of the Natal Museum 41: 181-202.

Stuckenberg, B. R., 2001. Pruning the tree: a critical review of classifications of the Homeodactyla (Diptera: Brachycera), with new perspectives and an alternative classification. - Studia Dipterologica 8: 3-41.

Stuckenberg, B. R. \& M. Fisher, 1999. A new species of Lampromyia Macquart, from Oman: the first record of Vermileonidae (Diptera) from the Arabian Peninsula. Annals of the Natal Museum 40: 127-136.

Yang, C., 1979. A new genus and species of wormlion from China (Diptera: Rhagionidae). - Entomotaxonomia 1: 83-89. [In Chinese with English summary.]

Received: 21 September 2001

Accepted: 18 January 2002 